\title{
A New Paradigm for Health Economics?
}

\author{
KJELD MØLLER PEDERSEN *
}

University of Southern Denmark

Culyer and Newhouse in their introduction to the Handbook of Health Economics ${ }^{1}$ noted that as a research program health economics seemed to be in good shape. "Moreover, its 'hard core' of neoclassical economics (especially welfare economics) is itself a part of the ongoing developmental agenda of the subject". They further observed that there is something in health economics for almost all kinds of health economists: "Powerful defenders of conventional methods and aggressive challengers; pure theorists and applied economists, those who undertake academic research for its own sake and those who see it as an instrument for the improvement of societies ...".

On the one hand Culyer and Newhouse's observations in all their generality are correct, but on the other hand it is more than worthwhile to stop and consider Bob Evans' critical, to some probably heretical, observations. Is health economics on the right track despite its academic and policy success? Are we able to understand and analyze health care systems as they exist in the real world as opposed to the fantasy world of welfare economics and general equilibrium theory? Is every approach, despite academic richness and freedom, equally relevant and applicable? The dialogue between Alice (in Wonderland) and the Cat pinpoints the issue and in reality is a question to all health economists: Alice: Would you tell me, please, which way I ought to go from here? The Cat: That depends a good deal on where you want to get to. Alice: I don't much care where. The Cat: Then it doesn't much matter, which way you go. Alice: ... so long as I get somewhere. The Cat: Oh, you're sure to do that, if only you walk long enough". Many have tried to address the question about the right direction ${ }^{2-9}$, but remarkably few over the past five to ten years. Therefore the think-piece by Robert Evans is most welcome.

The point of departure for Evans is positive, i.e. what a skeleton health care system looks like, i.e. an accounting relationship. The research question is what the physiology is like. Evans outlines three approaches ('paradigms') which all fail to provide a coherent set of answers to the many questions raised by such a simple diagram. At the outset it does not answer what health economics is about - or ought to be about. Rather the question is: how can this be analyzed theoretically and/or empirically. I concur with almost all Evans' points. Therefore, I will use the second paradigm outlined by Evans that of 'The mainstream economic' - held almost exclusively by professional economists or those with conventional economic training - as the point of departure for the following.

Two important challenges are still ahead for health economists: 1. Institutions matter, and 2. the proper role of market and government. They are not new, but still unresolved and hence need continual attention and reminding. Two hitherto unpublished works provide much of the material ${ }^{10,11}$. Furthermore, a paradigmatic shift in scholarly perspective, which ought to be the consequences of just these two points, does not occur, however, in response to simple exhortation. They occur when enough people find the old perspective unsatisfactory - because of a growing awareness of its inadequate explanatory power - and discover a new one that is both more enlightening and more interesting ${ }^{12}$. There are two issues at stake here: The reason why the old (read: traditional neo-classical 
perspective) perspective is inadequate, and is a better alternative in sight? A weakness of much criticism of the dominating neo-classical approach to a considerable extent is lack of a superior alternative.

\section{Institutions matter}

In neo-classical economics the terms 'institutional' and 'organizational' are used imprecisely, if at all, simply because the theory is devoid of institutions or at best are there implicitly, e.g. enforceable property rights. Welfare economics and general equilibrium theory are good cases. However, in transaction costs economics ${ }^{13-15}$ there is far more clarity. Menard ${ }^{16}$ says that "Institutions operate at a higher level of generalization than do markets and organizations: they delineate the rules of the game ... First, institutions are viewed as specific forms which are stable over long periods of time and which operate as constraints on agents. ... Second, institutions transcend individuals and organizations such as firms. They involve the implementation of an abstract set of rules, which are impersonal, in that they must apply to all members of specified categories and preclude. Third, institutions are normative in that they intend to establish distinctions between what is acceptable and what will be considered illegitimate. ... ${ }^{16}$. He goes on and defines 'An organization ... [as] an arrangement designed to make possible the conscious and deliberate coordination of activities within identifiable boundaries, in which members associate on a regular basis through a set of implicit and explicit agreements, commit themselves to collective actions for the purpose of creating and allocating resources and capabilities by a combination of command and cooperation'. ${ }^{16}$ Note that an organization is far more than the firm in neo-classical economics where it is reduced to a production function and preference function with net-profit as argument. An easy way to remember the above is to say that institutions define 'the rules of the game' while organization is about 'how the game is played'.

Derogatively many economists consider institutional and organizational details as 'descriptive', best left out or left to others to describe instead of understanding that their models and reasoning actually need these details to become relevant for policy purposes. Just a few observations: I have heard colleagues talk about 'cream skimming' in a Danish context, undoubtedly inspired by US work, apparently not knowing that this legally and rarely in practice is not possible in Denmark. Does legal custom, i.e. no-fault vs. culpa rules for negligence, not matter for understanding issues at hand? Or does the employment status of US 'hospital' doctors not matter' compared to salaried hospital doctors in most European countries when we develop for instance models of hospitals?

In 1987 Fuchs noted that some of the most useful work in health economics employs only elementary economic concepts but requires detailed knowledge of health technology and institutions ${ }^{17}$. And he repeated this message in his very readable 2000 article on the Future of Health Economics ${ }^{5}$. Evans, of course has also touched on the need for institutional details on several occasions. In his textbook Strained Mercy ${ }^{18}$ :

"the peculiar institutional features of health care delivery, if taken as a serious social response to genuine organizational problems rather than a series of accidents or nefarious plots by providers, force one back to a questioning of the usefulness of many of the standard tool and concepts of economic analysis, and a re-thinking of their underlying methodology" ${ }^{18}$, p. 323 
This is a strong, but relevant position. Just consider the Nordic health care systems with very strong government involvement (universal and largely tax financed based on fiscal federalism, speaking of institutional details) - and where resource allocation in the health care sector essentially is political resource allocation without help of the invisible hand. What is needed are theories of resource allocation through the political process (central and decentral), e.g. public choice/political economy approaches. For the purpose of health economics these challenges still have not been faced up to.

Evans in his 1998 essay on 'toward a healthier economics' once again noted the need for researchers to know institutional details. His observations are relevant to the theme of this section, even though maybe a bit unfair to Arrow, but again stressing the need for knowledge about real-world health care systems, however difficult, if not impossible to model elegantly in mathematical models:

"Unlike Arrow the theoretician, Kessel ${ }^{a}$ went out and studied the actual behaviour of U.S. physicians in considerable detail, and then described and interpreted that behaviour from an economic perspective. Many of his insights are still valid and not surprisingly they did not and do not all fit comfortably within conventional price theory. His contribution to our field, in substance and particularly in method, was far greater and Arrow's single paper, however theoretically elegant" ${ }^{20}$, p. 495

In other words: do health economists (unwittingly) look at and theorize about health and health care through the theoretical lenses provided by their training and not informed by reasonable thorough knowledge about the subject matter on hand? If the answer is largely affirmative, it poses a serious problem. Of course there has to be a balance between institutional detail and model assumptions to make models (mathematically) tractable. Too many institutional details can easily cloud the issues, i.e. cannot see the forest for trees, but only seeing the forest may miss important points about how to develop a forest professionally based on knowledge about tree growing. There is a joke about an economist being told that this is how things really are, how they work, to which the economist answers: 'but does it fit with economic theory' or alternatively, 'if the world is not like the model, so much the worse for the world'. This readily translates into Evans many relevant observations about positive and normative economics.

In his foreword to the book that celebrated Arrow's path breaking 1963 article $^{21}$ which ought to be compulsory reading for all health economists - Mark Pauly noted that there is a missing link 'a theory of what might be called institutional transformation' illustrated by the change from the idealized world of Marcus-Welby benevolent medicine to the current US situation'. Why he asks, by the logic of Arrow's argument, if the previous market failures began to evaporate, did not a more efficient market sector conquer more territory. 'there is a little (but only a little) evidence consistent with the theory'. The most important element, however, in the missing theory of institutional change is the absence of a definitive model of the most important non-market institution of all, the government. 'more generally, I would argue that the next frontier in health economics should be one in which public and private institutional choices are themselves explained' ${ }^{21}$, p. xii. However, at theory of institutional change presupposes attention to institutions - something that incidentally is found in neo-institutional theory ${ }^{22}$.

\footnotetext{
${ }^{\text {a }}$ Referring to Kessel's classic 1958 article on price discrimination ${ }^{19}$.
} 
As transition to the next section on government and market consider yet another example - and apologies for illustrating my points by example. However, it is useful to avoid erecting a straw man and provides documentation.

Despite realizing the importance of the question of institutional detail Joe Newhouse nevertheless asserts that using the US system, i.e. a particular institutional and organizational set-up, as a reference point basically is without problems:

"this book will mostly abstract from ... institutional differences among countries. That does not mean that differences are unimportant; indeed, accounting for them is essential when applying the theories and models ... to a particular context. But those theories and models are typically sufficiently general that they will apply to many institutional contexts. ... the illustrative examples I use come overwhelmingly from the United States. I apologize ... if the American focus causes ... problems. ... but the relatively greater availability of data about the American system has meant that the empirical studies in the literature come predominantly from the United States. Nonetheless, the same issues are found to a greater or lesser degree in every medical care financing and delivery system. The non-American reader may sometimes have to work a bit to relate the examples to the institutions of his or her country, but I believe that this almost always be possible",23, p. 6

Disregarding for the moment the parochial remarks about data and empirical testing the question is whether this assertion really holds up. Are the many studies of Medicare or Medicaid really relevant to for instance the Scandinavian countries, the UK or Germany in particular if carried out within a market economic framework?

The point of departure for Newhouse's book is the undesirable properties associated with 'administratively set prices', and the solution is more reliance on competitive arrangements with (more) competitively set prices. However, if one has a dominant third party payer - like in the Scandinavian countries, isn't administratively set prices a fact of life? One can of course argue, mainly theoretically that the virtues of more or less competitively set prices are considerably, but does this really hold both theoretically, with a tax financed system, or empirically?

\section{Government, markets, and competition}

However, turning Evans' description of Hume's Law (or even better: Hume's Guillotine), i.e. that one cannot (logically) derive "ought" from "is", upside down, one should be careful not to equate 'is', i.e. existing institutions and organizations, with being 'good enough', 'right' or 'immutable', a trap that is easy to be caught in. This in turn raises the question about the foundation on which to base changes of the existing situation. In other words: What should be the measuring rod, the standard for comparison? This is not, without being very subtle, to be equated with 'how things ought to be', but nevertheless is often the case when mainstream economists use the competitive market solution as a measuring rod.

Mainstream (health) economists ${ }^{\mathrm{b}}$ apply their methods of analysis in much the same way that a boy with a hammer thinks that everything looks like a nail. It is, however,

\footnotetext{
${ }^{\mathrm{b}}$ Winston Churchill is quoted for saying that 'all generalizations are wrong with the possible exception of this one'. There are of course many exceptions to some of the following statements. However, it does not change the fact that it holds for a majority of health economists, in particular from the U.S. Furthermore, if
} 
necessary to supplement the tool set, if all phenomena are not nails, but if one has been socialized to consider the hammer as the only tool, and that all phenomena are nails, one would never think that it should or could be differently. Economists today are (still) trained in an economic tradition that quite naturally is developed to understand market economics - allocation by the price mechanism - but rarely trained in non-market methods and resource allocation via the political mechanism i.e. public choice, or the resource allocation that takes place within (vertically) integrated firms, e.g. neoinstitutional economics/transaction cost economics.

As above excerpts of texts by economists (I respect) underpin my points below and provide documentation. One may claim that obvious points are rehashed, but on the other hand, paradoxically, it still appears to be needed.

Two well-known textbooks illustrate the choice of comparison standard, and hence, how budding health economists are trained to think: Consider Folland, Goodman and Stano: 'Throughout this book, we have emphasized the role that markets can play in providing health care. We have also generally taken economic efficiency, proven in theory by perfectly competitive markets, as a standard against which to judge the costs and benefit of policies", ${ }^{24}$ (p. 495). Zweifel and Breyer more guardedly assert, "When correctly interpreting the assertions of welfare theory, one finds that for an optimal allocation of resources there need not be a competitive market at every level; it is sufficient that economic subjects behave as if they are acting in such a system. In this view, competition and public regulation do not constitute polar cases; rather, public regulation may be used to create conditions for the actors to behave as if they were in competition. The key word here is incentives. Therefore, the objective of public regulation should be to set the incentives such that actors use resources efficiently even where the market mechanism cannot work. ... Another important point is the role of competition. Competition necessarily goes along with attempts of suppliers to call consumers' attention more or less ostentatiously to their products. ... Competition may thus contribute to efficiency in health care as elsewhere, provided that the demanders of health services can make their choices consciously and without the pressure of an emergency. ... By all means, there is a role for competition at the level of entire systems of provision" 25 (p. 364-65). - We disregard here that the first sentence of the quote probably only is partly correct. The statement only serves as documentation of prevailing interpretations and positions. And furthermore on p. 370: "that developments in health care should be increasingly determined by market forces, which are expected to bring forth even more organizational innovations, some of them different from anything conceivable at present..."

Two observations are in place: The superiority of market solutions/competition in health care is assumed a priori by reference to theoretically derived results (that actually no longer holds, cf. below) ${ }^{\mathrm{c}}-$ despite the fact that market solutions - in particular in the perfect competition sense used a measuring rod - never has been the dominant mode of operations anywhere, maybe not even excepting the US. Secondly, equity is disregarded ${ }^{25}$, ${ }^{26}$, maybe by implicit reference to the separation theorem concerning the two fundamental theorems of welfare economics - knowing, however, that this basically is impossibly, i.e. there is a trade-off between efficiency and equity.

all exceptions should be considered, it would be virtually impossible to write a comment like this one where some generalizations are inevitable

${ }^{c}$ For the record: I am not against markets and competition - I have even on occasion been called supporter for more market in health care. Rather, I am against inconsequential and misuse of economic thinking and call for the development of other measuring rods in health care than that of perfect competition. 
Arrow already in 1963 hinted at problems:

"If, on the contrary, the actual market differs significantly from the competitive model, or if the assumptions of the two optimality theorems are not fulfilled, the separation of allocative and distributional procedures becomes, in most cases, impossible" ${ }^{27}$, p. 943.

And with the paradigmatic shift in the wake of the advent of information economics it becomes clearer and theoretically well-proven. Information economics - see Stiglitz for a good overview ${ }^{28-30}$ - has shown that the welfare theorems do not hold once even small information costs are introduced, already hinted at by Arrow, i.e. thoroughly debunking the prima facie normative argument for the efficiency superiority of competition. Stiglitz writes:

"These results ... had profound implications for two well-established doctrines. First, they implied that the economy could not be efficiently decentralized. Second, ... they established that the standard separation of equity and efficiency did not hold when information was imperfect. Thus, both the Second Fundamental Theorem of Welfare Economics and Coase's theorem (conjecture) on the irrelevance of the distribution of property rights, were overturned" ${ }^{31}$, p. 1458.

The impossibility of separating efficiency and equity has been shown theoretically ${ }^{\mathrm{d}}$. However, many (health) economists persist in the belief that a separation is possibly, but probably carry over misinterpreted theory, and/or unsubstantiated beliefs (as opposed to analysis or empirical evidence that it can be separated). Consider the following from an otherwise good paper:

"Governments should establish institutions to finance health care and pool risk, rather than relying only on the free market. However, the way in which the market and government can work efficiently and appropriately varies by function, for example, financing versus the provision of health care. ... As market competition is capable of addressing only the efficiency issue, the government has to be responsible for the equitable financing and distribution of essential health goods" ${ }^{33}$, p. 8

Cutler writes that public intervention in medical care is pervasive, for good reason ${ }^{34}$. That undoubtedly is true. Elsewhere he states - like it was a documented fact:

"the classic trade-off in economics is between equity and efficiency ... care:

Efficiency was not a great concern when health systems were established;

\footnotetext{
${ }^{\mathrm{d}}$ Even if it were the case, one should always remember the theory of the second best ${ }^{32}$, i.e. Lipsey and Lancaster already in 1956 showed that if one optimality condition in an economic model is not satisfied, it is possible that the next-best solution involved changing other variables away from the ones that are usually assumed to be optimal! For practical purposes this may mean that if we have an economy with market failure in one sector there can actually and paradoxically be a decrease in efficiency due to a move toward greater market perfection in another sector.
} 
countries were content to have inefficient medical-care systems provided the treated all equally" ${ }^{35}, 881$.

Do we actually know that systems that historically and today stress equity like in Scandinavia and the UK also were and are inefficient, and do we know that systems that to a considerable extent disregard equity and universalism are efficient, e.g. the US? And the clincher: do we know that public integrated systems are more inefficient than private insurance/provision systems (theoretically or empirically)? We are here up against two challenges: A prejudiced judgement about presumed inefficient publicly provided health services. Assuming that they are not efficient by the standards of the perfectly competitive model, shouldn't they in a sense, by the same standards, be inefficient due to efficiencyequity trade-off?! Secondly, we are suffering from a lack of a theory of public provision and resource allocation by the political mechanism.

Culyer already back in $1971^{36}$ noted: “. . . an itemization of its [... health care] characteristics tells us nothing about the most efficient way of producing or allocating it. ... choice of institutions is never a choice between an imperfect one and a perfect one.... we need a well-developed positive theory of non-profit institutions from which implications comparable to those of the received theory of the firm can be derived". And today we still do not have such a theory - instead, based on the US experience, it is claimed that non-profit hospitals act pretty much like for profit hospitals.

\section{A new research agenda?}

The critics of the welfare economics-general equilibrium-perfect competition paradigm have not provided an alternative paradigm, despite their very valid points of criticism. It would be unfair to expect and require this, but on the other hand a research agenda for the future needs to be established. It would of course be a non-sequitur conclusion that nonmarket solutions then are to be preferred in that there are no reasonably developed theories of government provision and resource allocation. The naïve welfare economics based version that market failure provides to some not only a prima facie justification for public provision but also that it will, implicitly, correct the ills of market failure is of course wrong because there are also government failures. The real point is that we must compare 'imperfect with imperfect' not imperfect with a utopian perfect and normative solution and develop theories about this.

Fuchs in 2000 said that the future of health economics depends heavily on how well health economists carry out two distinct albeit related missions: a. enhancing understanding of economic behavior and $b$. providing valuable input into health policy and health services research. As regards the first point five areas for intensified research with the potential for making a contribution to economics in general was identified:: Endogenous technology and preferences, social norms, principal-agent problems, behavioral economics, and measurement and analysis of quality of life. However, these important areas as such will not provide an adequate and partly new paradigm for health economics. We need to focus on non-market methods and resource allocation via the political mechanism i.e. public choice, or the resource allocation that takes place within (vertically) integrated firms, e.g. neo-institutional economics/transaction cost economics. 
Transaction costs economics ${ }^{14}, 15,37, \mathrm{TCE}$, in no way is the answer to all the problems listed above ${ }^{\mathrm{e}}$. However, it may be a potentially fruitful approach to several of the problems and analytic challenges in health economics, in particular the use of comparison of imperfect alternatives when choosing forms of governance, and it also pays attention to institutions and organizational details along with resource allocation and contracting problems in hierarchies. In a sense it is squarely within 'traditional economics', but uses a somewhat different analytical apparatus ${ }^{\mathrm{f}}$ and focuses on other issues, introduces different behavioral assumptions (bounded rationality) and do not as a more general principle rely on normative arguments. Intellectually many fundamental ideas can be attributed to Coase, starting with his 1937 article on the nature of the firm ${ }^{38}$ where he introduced the notion of transaction costs. He basically asked: why do firms exist? Part of the answer was: to economize on transaction costs - and Arrow actually traces market failure to a question of transaction costs.

There are two levels of TCE (or the new institutional economics): 1. The institutional level, which includes both formalized aspects (law, polity, judiciary) and an informal dimension (customs, mores, norms). This is about the 'rules of the game'. Nobelprize winner Douglass North has made important contributions ${ }^{22,39}$. 2. Governance issues (markets, firms, bureaus) are about 'how the game is played'. Behind point 2 is a very elaborate theory of contracting, indeed economic man is substituted with contracting man characterized by bounded rationality and opportunism. The theory of institutional change that Mark Pauly called for would be explored under point 1.

Space does not allow further elaboration, but there is a great potential for relevant research by applying TCE. ${ }^{10}$

* Correspondence to: Kjeld Møller Pedersen, Professor, Health Economics and Health Policy, University of Southern Denmark. E-mail: kmp@sam.sdu.dk

\footnotetext{
${ }^{\mathrm{e}}$ Not that it matters, but no less than three Nobel Prize-winning economists can be invoked: Douglas North, Ronald Coase and Oliver Williamson - and possibly also a fourth, Herbert Simon.

${ }^{\mathrm{f}}$ Experience has shown that the introduction of a somewhat foreign terminology compared to what is taught in traditional microeconomics causes problems, e.g. governance, discrete structural analysis or ideas like trust and authority - and may provide one of the answers why such obvious ideas have been slow in entering health economics.
} 


\section{References}

1. Culyer A, Newhouse J. Handbook of Health Economics. Amsterdam: Elsevier; 2000.

2. Coast J. The appropriate uses of qualitative methods in health economics. Health Econ 1999;8(4):345-353.

3. Coast J, McDonald R, Baker R. Issues arising from the use of qualitative methods in health economics. J Health Serv Res Policy 2004;9(3):171-176.

4. Edwards RT. Paradigms and research programmes: is it time to move from health care economics to health economics? Health Econ 2001;10(7):635-649.

5. Fuchs VR. The future of health economics. J Health Econ 2000;19(2):141-157.

6. Mannion R, Small N. Postmodern health economics. Health Care Anal 1999;7(3):255-272.

7. Maynard A, Kanavos P. Health economics: an evolving paradigm. Health Econ 2000;9(3):183-190.

8. Phelps CE. Perspectives in health economics. Health Econ 1995;4(5):335-353.

9. Williams A. Priorities and research strategy in health economics for the 1990s. Health Econ 1993;2(4):295-302.

10. Pedersen K. Health economics reconsidered: is transaction costs a relevant paradigm? (availabel on request). Paper delivered at the 25th Nordic Health Economists' Study Group Meeting, Iceland. 2004.

11. Pedersen K. The poverty of health economics? Reforms in Scandinavia - lesson(s?) for the rest of the world. (available on request). Paper delivered at the 28th meeting of the Nordic Health Economics' Study Group, Tartu, Estonia. 2007.

12. Evans RG, Barer ML, Marmor TR. Why are some people healthy and others not? The determinants of health of populations. New York: Aldine de Gruyter; 1994.

13. Williamson Oliver E. The Mechanisms of Governance. Oxford University Press, Oxford 1996 .

14. Williamson Oliver E. The Economic institutions of capitalism. New York: The Free Press; 1985.

15. Williamson O. The New Institutional Economics: taking stock, looking ahead. The Journal of Economic Literature 2000;38(3):595-613.

16. Menard C. Markets as institutions versus organizations as markets? Disentangling some fundamental concepts. Journal of Economic Behavior and Organization 1995;28:161-182.

17. Fuchs V. Health Economics. In: Eatwell J, Milgate M, Newman P, editors. The New Palgrave: Social Economics. New York and London: W.W. Norton; 1989:119-129.

18. Evans RG. Strained Mercy - the economics of Canadian Health Care. Toronto: 1984. 
19. Kessel RA. Price discrimination in medicine. Journal of Law and Economics 1958;1(2):2053.

20. Evans R. Toward a healthier economics. Reflections on Ken Bassett's Problems. In: Barer M, Getzen T, Stoddart GL, editors. Health, Health Care and Health Economics. Perspectives on Distribution. Chichester: Wiley; 1998:465-500.

21. Hammer PJ, Haas-Wilson D, Sage WM. Kenneth Arrow and the changing economics of health care: "Why Arrow? Why now?". J Health Polit Policy Law 2001 Oct 1926;835-849.

22. North DC. Institutions, institutional change and economic performance. Cambridge og New York: Cambridge University Press; 1990.

23. Newhouse J. Pricing the priceless. A health care conundrum. Cambridge, Mass.: MIT Press; 2002.

24. Folland S, Goodman A, Stano M. The Economics of Health and Health Care (second edition). Upper Saddle River, NJ: Prentice Hall; 1997.

25. Zweifel P, Breyer F. Health Economics. Oxford: Oxford University Press; 1997.

26. Reinhardt U. Abstracting from distributional effects, this policy is efficient. In: Barer ML, Getzen TE, Stoddart GL, editors. Health, Health Care and Health Economics.Perspectives on distribution. New York: Wiley; 1998.

27. Arrow K. Uncertainty and the welfare economics of medical care. American Economic Review 1963;53(2):941-973.

28. Stiglitz JE. Information and the Change in the Paradigm in Economics. American Economic Review 2002;92(3):460-501.

29. Stiglitz JE. Information and the Change in the Paradigm in Economics, Part 1. American Economist 2003;47(2):6-26.

30. Stiglitz JE. Information and the Change in the Paradigm in Economics, Part 2. American Economist 2004;48(1):17-49.

31. Stiglitz J. The contributions of the economics of information to the twentieth century economics. The Quarterly Journal of Economics 2000;115(4):1441-1478.

32. Lipsey RG, Lancaster K. The general theory of second best. Review of Economic Studies 1956;24(1):11-32.

33. Hsiao W, Heller PS. What Should Macroeconomists Know about Health Care Policy? Washington D.C: International Monetary Fund; 2007.

34. Cutler D. Health Care and the Public Sector. In: Auerback AJ, Feldstein M, editors. Handbook of Public Economics, volume 4. Amsterdam: North Holland; 2002:2143-2243.

35. Cutler D. Equality, efficiency, and market fundamentals: the dynamics of international medical-care reform. Journal of Economic Literature 2002;40(3):881-906.

36. Culyer Anthony J. The nature of the commodity 'health care' and its efficient allocation. Oxford Economics Papers 1971;23:189-211. 
37. Williamson O. Transaction Cost Economics: The Natural Progression. American Economic Review 2010;100(3):673-690.

38. Coase R. The nature of the firm. Economica N.S. 4, 386-405. 1937.

39. North DC. A transaction cost theory of politics. Journal of Theoretical Politics 1990;2(4):355-367. 